\title{
Resistance of Epoxypolymer with 2 - 5 wt\% Nanosilica in Aggressive Acid Medium
}

\author{
Dmitro L. Starokadomsky, Igor G. Telegeev \\ O. O. Chuiko Institute of Surface Chemistry, Kyiv, Ukraine \\ Email: Stard1@mail.ru
}

Received May 22, 2012; revised June 24, 2012; accepted July 5, 2012

\begin{abstract}
The swelling dynamic and epoxy resin structure changes of nanosilica (NS) with different specific surface in concentrated nitric acid were studied. It is established that with increasing of specific surface area of unmodified NS swelling degree decreases and stability of the composite in the acid goes up. Resistance of NS to the $\mathrm{HNO}_{3}$ can be achieved by choosing the optimal concentration and modifications of NS's surface. According to electron microscopy and X-ray diffraction, the structure of composite can be changed due to appearance of ordered structural zones.
\end{abstract}

Keywords: Nanosilica (NS); Epoxypolymer (EP); Nitric Acid (c.HNO 3 ); Swelling Degree (q); Life-Time (L); Destruction; TEM-Images

\section{Introduction}

Introduction of nano- and micro-additives is commonly used for improvement of industrial compositions properties [1-19]. One promising areas of the research is the study of nano-additive's impact on resistance to aggressive environment and atmosphere. Effect of NS-surface structure on chemical resistance and durability of polyepoxide composites continues to be debated. For example, nanosilica $(0.5-3 \mathrm{wt} \%)$ is used as an additive for epoxy matting floor covering [2-10], in the paint [1,5], dental [4], and electrical [7] industry. Silica additives provide incensement of thermal stability $[11,18]$, and chemical resistance to water $[9,10,13]$, organic $[10,17]$ and other environments $[8-10,12,16,19]$. The influence of atmospheric effects on the processes of structure and properties of epoxy coatings has also been studied [1]. Improvement of properties and increase of the chemical resistance of composites are achieved by NS surface modifying and defining of optimal concentration of NS [5-11] and other dispersed fillers [3].

For today, there is a lack of data about the influence of specific surface area $(\mathrm{S})$ of nanosilica on the chemical properties of the composites. Different works [8-10,15] have shown that the specific surface area is an essential factor with a significant influence on the properties of epoxy composites. However, the study of stability in aggressive environment has showed that the dependence of the chemical resistance from $\mathrm{S}$ is hard to establish. For example, some articles $[8,10]$ have reported about failure to establish a correlation between the swelling rate and $\mathrm{S}$ in water and hydrochloric acid, perhaps due to the temperature of the experiment $\left(20^{\circ} \mathrm{C}-25^{\circ} \mathrm{C}\right)$. Here we present investigation results of the effect of dispersed fillers surface modification on the swelling and chemical resistance of NS.

\section{Experimental Part}

A study on the degree of dependence of swelling (q) of the concentration, nature and specific surface of nanosilica ("Aerosil" type) was carried out in this paper. Studies were carried out for 1 month at $11^{\circ} \mathrm{C} \pm 2^{\circ} \mathrm{C}$. The mass of samples were $85 \pm 10 \mathrm{mg}(\mathrm{U})$ and $110 \pm 10 \mathrm{mg}$ $\left(\mathrm{U}^{\prime}\right)$, for which data were averaged.

Standard epoxy (EP) matrix based on dyanepoxyresin ED-20 (see formula (1), UfaKhimProm Russia product) $+12.5 \mathrm{wt} \%$ of polyethylentpolyamine (PEPA), was filled with $\mathrm{C}=2 \mathrm{wt} \%$ (or $\mathrm{C}=5 \mathrm{wt} \%$ ) by nanosilica "Aerosil" A-50, A-100, A-175, A-300, A-455 (where the number corresponds to the specific surface area $\mathrm{S}$ in $\mathrm{m}^{2} / \mathrm{g}$ ). Aerosil were used: A-50 - produced by Degussa (Germany), others-the own production of Institute of Surface Chemistry, Kalush factory (licensed production of nanosilicas TM "Asil" and "SILIKS" (with $100<\mathrm{S}<$ $400 \mathrm{~m}^{2} / \mathrm{g}$ [4a]). Aerosil modified by acrylate silane (A-174), complex "methyltriethoxysilane-polyester resin" and complex "methyltriethoxysilane MTES - epoxy resin ED-5" were used. Aerosils were introduced into epoxy matrix, mixed and incubated for 1 - 2 months, time to time carrying additional mixing of heated composition. At the end of the process the "ripening" com- 
position was heated and introduced $12.5 \%$ of PEPAintensive stirring for $5-10 \mathrm{~min}$, to reduce the air bubbles in the batch mixing carried by spiral movements of the pointed stick ("mini-mixer"), then to maximize the removing of single air bubbles composition briefly heated $\left(70^{\circ} \mathrm{C}-90^{\circ} \mathrm{C}, 2-3 \mathrm{~min}\right)$. At the end of the homogenization of the air-cured with subsequent exposure of the samples cured for 1 - 2 months. After that, without additional heat treatment, the EP-samples were placed in corrosive liquids.

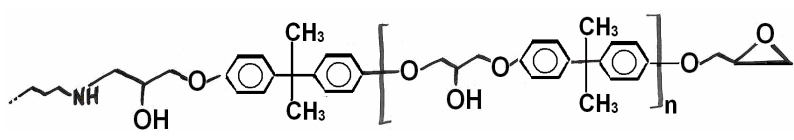

$+\mathrm{HNO}_{3} \rightarrow \mathrm{NO}_{2}+\mathrm{H}_{2} \mathrm{O}+\mathrm{CO}_{2}+$ products of destruction

For study of the swelling of filled compositions, the lenticular samples $1 \mathrm{~cm}$ in diameter and $2-3 \mathrm{~mm}$ thick have been used. They were immersed into a concentrated nitric acid $\left(\mathrm{c} . \mathrm{HNO}_{3}\right)$ in the polyethylene-stoppers crucibles. Swelling was estimated by change in weight of composites $\mathrm{q}=\left(\mathrm{m}_{1}-\mathrm{m}_{\mathrm{o}}\right) / \mathrm{m}_{\mathrm{o}} \times 100 \% \quad\left(\mathrm{~m}_{1}\right.$ and $\mathrm{m}_{\mathrm{o}}$-current and the initial sample mass) after $40-60 \mathrm{~min}$ of drying at room temperature. Initial and filled samples were studied by electron microscopy (SEM) and X-ray analysis. The lifetime $\mathrm{L}$ of the sample was defined as the time of transition from solid to viscous (not weighed) state.

\section{Results and Discussion}

\subsection{Nature of Change of EP-Samples under the Influence of the CA Depending on the Content of Silica}

Visual analysis points out that processes of decomposition of EP-composite in $\mathrm{c} . \mathrm{HNO}_{3}$ take place with obvious formation of low-molecular products and $\mathrm{NO}_{2}$, which leads to a rapid color change (browning) of the samples. Thus, at day 2 samples lose their transparency and colorless (or whitess), but almost all keep the original shape and luster (Figure 1(a)). On the $4^{\text {th }}$ day some of the $\mathrm{SiO}_{2}$ filled samples begin to delaminate. As you can see in Table 1, the process of swelling of unfilled PE sample $(\mathrm{U}+\mathrm{U}$ ', shown in Table 1 and Figures 2-5) proceeds rapidly. After 1-day of exposure in c. $\mathrm{HNO}_{3}$ it swells by $21.5 \%$, after 4 days — on $40 \%$, after a week - by $70 \%$ $80 \%$.

\subsection{The Swelling Curves: Influence of Silica}

The curves of swelling in c. $\mathrm{HNO}_{3}$ did not have an asymptotic plot of saturation so we would not be able to calculate their basic characteristic like coefficient of diffusion D. In this case, real rate of swelling W (\%/days) was elected as a characteristic of process (Table 1).

Figure 1(b) shows the swelling process can be divided into 4 stages.
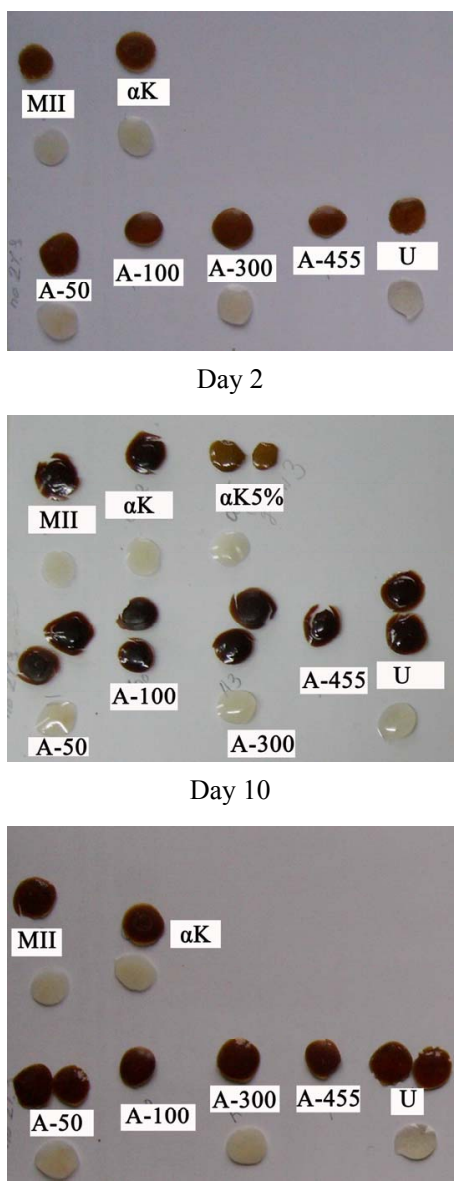

Day 4

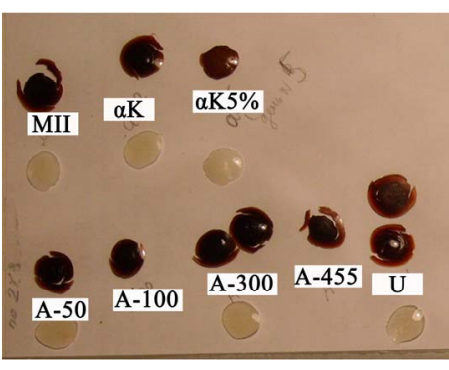

Day 12

(a)

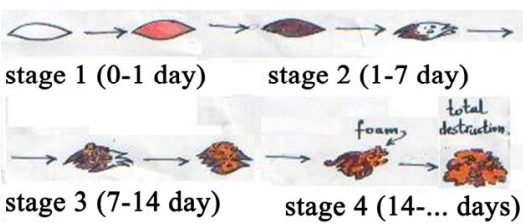

(b)

Figure 1. (a) Samples ( $2 \mathrm{wt} \%$ of silica) before (white) and after (dark) exposure in concentrated $\mathrm{HNO}^{3}$ during 2, 4, 10 and 12 days. Designations: ak: silica A-100/modif.by acrylsilane A174; ak5\%: 5 wt\% of silica A-100/modif.by acrylsilane A174; MII: silica A-100/modif.by complex "methyltriethoxysilane MTES: epoxyresin"; =: silica A-50; A3: silica A-300; A4: silica A-455; A100: silica A-100; U: unfilled polyepoxide; (b) Stages of swellling (decomposition) of PEC-template in c.HNO $\mathrm{H}_{3}$. 
1) At the first stage (0 - 1 days) the rate of swelling reached $20 \%$ per day. The first stage is characterized by high speed of penetrating of acid solution in pores of EPcomposite; yellowing of samples suggests about the primary chemical destruction processes.

2) At the second stage ( $1-7$ days), the process is stabilized, and $\mathrm{W} \approx 7 \%$ /day. It shows complete filling of pores in the polymer by c. $\mathrm{HNO}_{3}$ and the continuation of the normal process of swelling. Simultaneously the process of destruction is accelerated (browning of the samples) (Figure 1(b)).

3) At the third stage (7 - 14 days), swelling reaches the $80 \%-100 \%$, and the sample transforms to elastic pasty mass with bubbles of $\mathrm{CO}_{2}$ and $\mathrm{NO}_{2}$, with brown-yellow color.

4) At the fourth stage the sample transforms to the foam forming yellow solution.

Hence a resistance of unfilled EP-composite c. $\mathrm{HNO}_{3}$ composes 1 - 2 weeks, and due to process of decomposition, samples have increased their masses almost in two timesaverage is $180 \% \pm 10 \%$.

The influence of non-modified nanosilica on q depends on their specific surface area. As shown in Table 1 and Figures 2 and $\mathbf{3}$, an introduction of $2 \%$ of nanosilica into the composition leads to decreasing of $\mathrm{q}$, and not increase the lifetime of the composition. The value of this decreasing $\Delta \mathrm{q}=\mathrm{q}_{\mathrm{U}}-\mathrm{q}\left(\mathrm{q}_{\mathrm{U}}\right.$-for unfilled, $\mathrm{q}$-for current filled EP-composite) can reach $20 \%-25 \%$ for A-300, and consists $3 \%-10 \%$ for other silica. Since 1 day of exposure, we also note a correlation of $\mathrm{q}-1 / \mathrm{S}$ ( $\mathrm{S}$ - specific surface of silica, $\mathrm{m}^{2} / \mathrm{g}$ ) - reduction of the $\mathrm{q}$ and $\mathrm{W}$ with a increasing of S. In the first few hours (for example, 0.06 days, Table 1) filled samples swell more eagerly than unfilled. It suggests about changes of macro-porosity of the composites after filling.

Table 1. Stages of swelling in c.HNO $\mathrm{H}_{3}$ for EP-composites.

\begin{tabular}{cccl}
\hline $2 \mathrm{wt} \%, 10^{\circ} \mathrm{C}$ & Days & $\mathrm{W}_{\text {medium }}, \%$ day & \multicolumn{1}{c}{ Visual changes } \\
\hline 1 & $0-1$ & 20 & Yellowing \\
2 & $1-7$ & 7 & Browning \\
3 & $7-12$ & 4 & Elastization, delamination, first micro-bubbles \\
4 & $12-14$ & 5 & Foaming, viscosity, partially solution \\
5 & $14-\ldots$ & - & Fully decomposition or solution \\
\hline $5 \mathrm{wt} \%, 25^{\circ} \mathrm{C}$ & & & \\
\hline 1 & $0-1$ & 20 & Yellowing \\
2 & $1-5$ & 5 & Browning \\
$2 \mathrm{a}$ & $5-7$ & 10 & Elastization, delamination, first micro-bubbles \\
3 & $7-12$ & 6 & Active delamination and numerous microbubbles \\
4 & $12-15$ & 5 & Foaming, viscosity, partially solution \\
5 & $15-\ldots$ & & Fully decomposition or solution \\
\hline
\end{tabular}

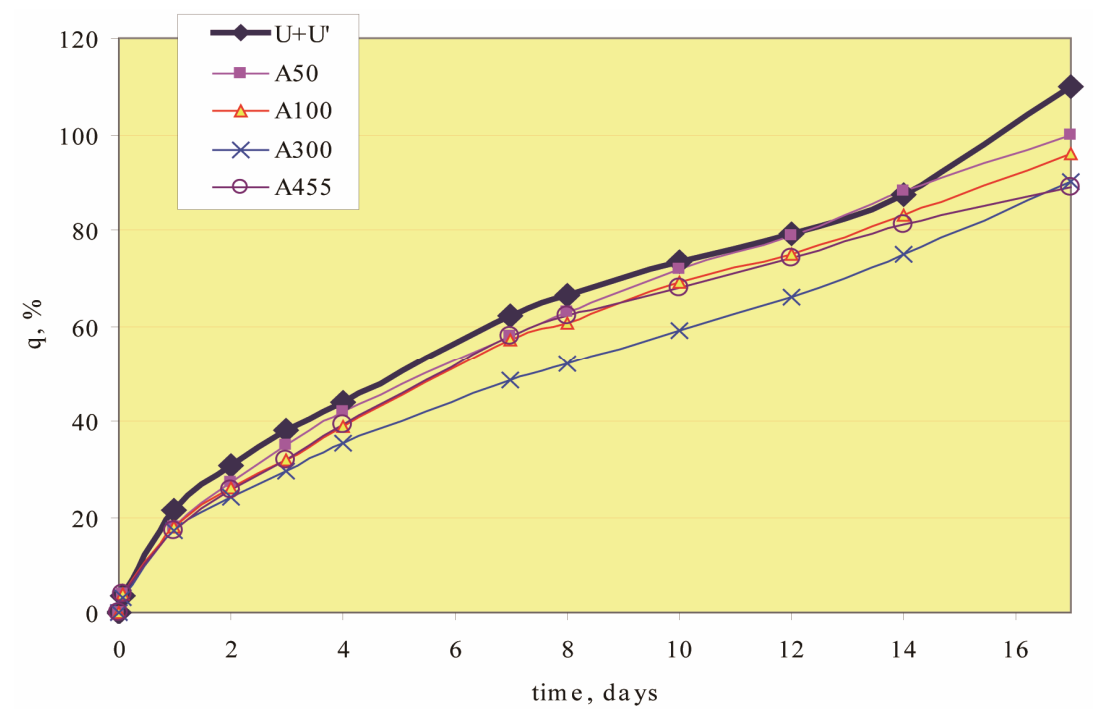

Figure 2. The curves of swelling $\left(11^{\circ} \mathrm{C}\right)$ in the concentrated $\mathrm{HNO}_{3}$, samples with $2 \mathrm{wt} \%$ of unmodified NS. 
Swelling-curve of composite with low-disperse A-50 copies the shape of the curve for unfilled sample, i.e., the effect of low-disperse silica is insignificant. During the first day the difference is not significant ( $q$ indexes are the same) for NS brands A-50 and A-100, when the rate of swelling of the sample with the A-100 is reduced. The influence of high-dispersed silica A-300 ( $\left.\mathrm{S}=340 \mathrm{~m}^{2} / \mathrm{g}\right)$ for $\mathrm{q}$ is noticeably from the first minutes of exposure in c. $\mathrm{HNO}_{3}$, and at all stages q $\square \quad \mathrm{q}_{\mathrm{U}}$ (after filling q decreases on $20 \%-23 \%$ ). Note that ultra dispersed A-455 satisfies correlation " $\mathrm{q}-1 / \mathrm{S}$ " only at $\mathrm{t} \leq 1$ and $\mathrm{t} \geq 17$ days (Figure 3).

Experimental data shows that filling by $2 \mathrm{wt} \%$ of modified silica cannot strengthen composite resistance to swelling in c. $\mathrm{HNO}_{3}$. As can be seen from Figure 4, filling with $2 \%$ of modified silica does not lead to a strengthening of chemical resistance, as $\mathrm{W} \approx \mathrm{W}_{\mathrm{U}}$, and life-time $\mathrm{L} \leq \mathrm{L}_{\mathrm{U}}$. By increasing concentration $\mathrm{C}$ from 2 $\mathrm{wt} \%$ to $5 \mathrm{wt} \%$ of modified silica (sample AK5), the chemical resistance of composite is increased. This is clear from the substantial (in 1.5 times) reduction of swelling for sample "epoxyresin $+5 \mathrm{wt} \%$ A-100/mod.A174" (sample ak5, Figure 4).

The results of swelling for $5 \mathrm{wt} \%$-filled EP-composite at $25^{\circ} \mathrm{C}(\mathrm{Q})$ confirm a possibility to improve durability in c. $\mathrm{HNO}_{3}$ by modifying the surface of silica. The unmodified A-300 actc as a "worsening additive", due to increasing of swelling and decreasing of life-time of EPcomposite (Figure 5). But modification by A-300 by contrast enhances effect. The most part of "EP + mod. A-300" has a smaller swelling $\mathrm{q}<\mathrm{q}_{\mathrm{U}}$ (compared with $\mathrm{q}_{\mathrm{U}}$ for unfilled EP) at $1-12$ days.

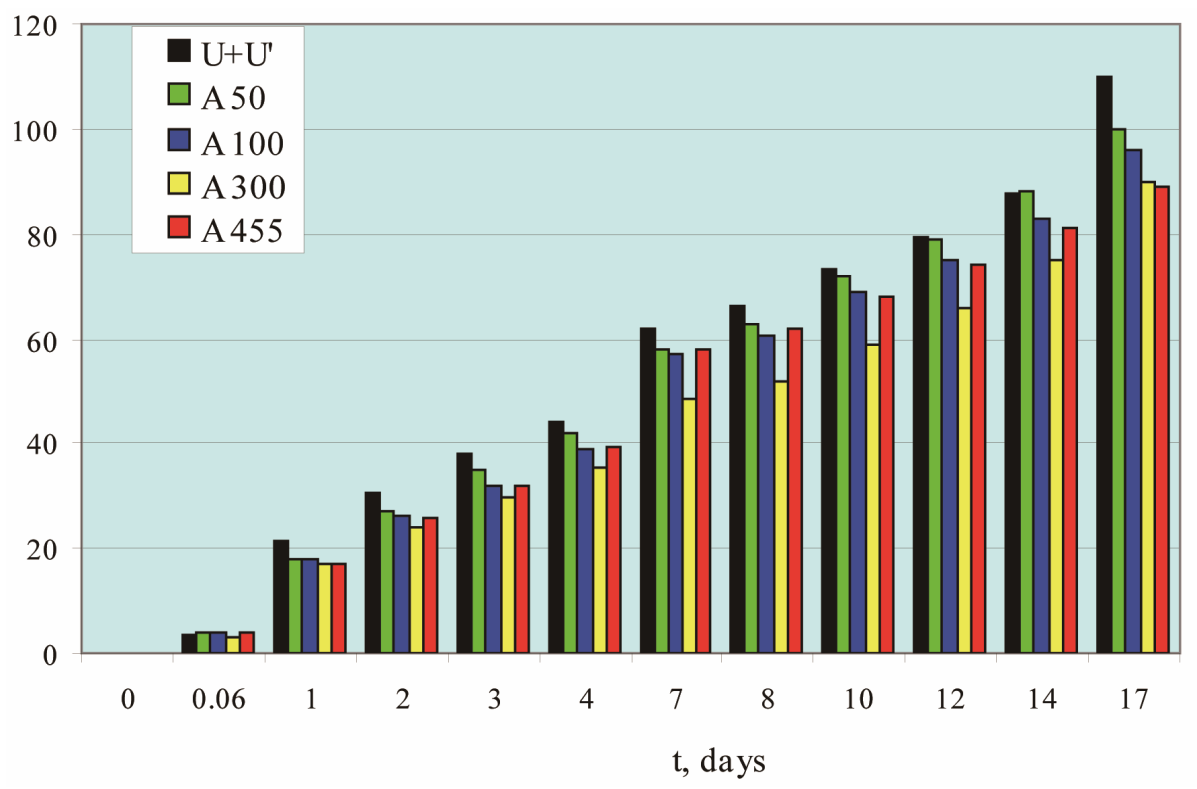

Figure 3. Histogram of the samples with $2 \mathrm{wt} \%$ unmodified aerosil swelling (black column—averaged values—of $q$ for the unfilled samples).

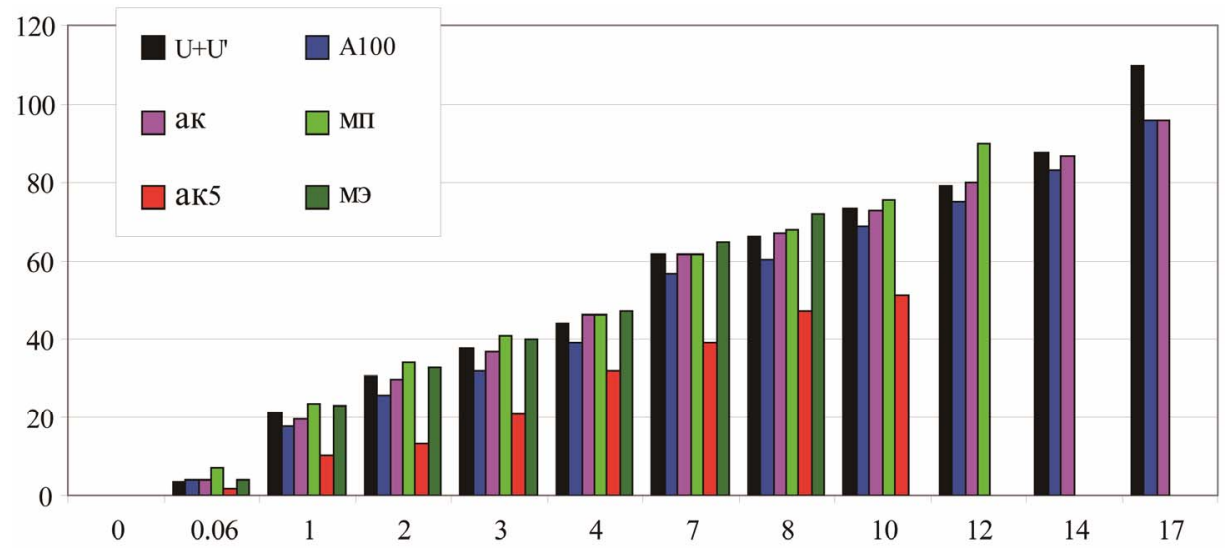

Figure 4. Histogram of swelling of the samples with 2 wt\% (for ak5-5 wt\%) A-100 and its modified forms (black column - the average value for the unfilled samples). 


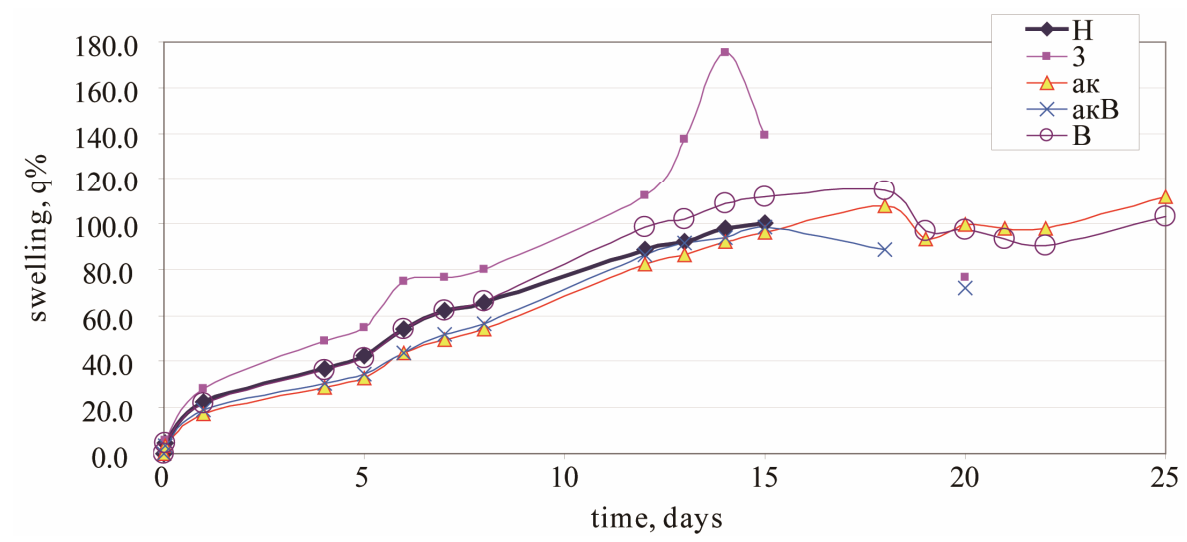

Figure 5. Swell curves in c. $\mathrm{HNO}_{3}\left(25^{\circ} \mathrm{C}\right)$ for EP-templates with $5 \mathrm{wt} \%$ of silica: $\mathrm{H}$ : unfilled; 3: aerosil A-300; ak: A-300/ mod.acrylsilane A174 (monolayer); akB: A-300\mod.acrylsilane A174 + olygoacrilate Bis-GMA; B: A-300/mod.olygoacrilate Bis-GMA (monolayer).

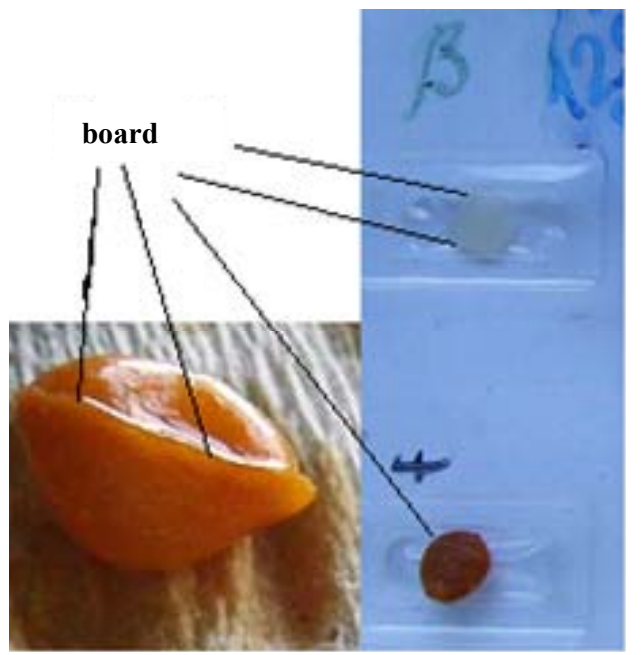

Figure 6. The visual shape of EP-template "B"-initial thick (up) and after 12 days in $\mathbf{c} . \mathrm{HNO}_{3}$ (ball-like).

The maximum on curve "3" (for A-300) at 14 days and weak maximums for other curves can have next explication. The presence of inorganic phase (silica) causes the penetration of $\mathrm{HNO}_{3}$-molecules into a polymer network to increase. At definite time, the excess of swelling leads to the degradation and destruction of polymer, because of q-value decreasing. For modif.A-300 (curves ak, akB, B on Figure 5), hydrophility of NS-phase is weaken (compare unmod.A-300) and maximum peaks are less (Figure 5). The time 8 days can estimate as boarder time, after that the increasing of $\mathrm{W}$ takes place, and $\mathrm{q} \rightarrow \mathrm{qu}_{\mathrm{U}}$ (in some cases $\mathrm{q}>\mathrm{qu}_{\mathrm{u}}$ ). After 12 days (analogically to $2 \mathrm{wt} \%$ at $10^{\circ} \mathrm{C}$, Figure 4) $\mathrm{q} \geq \mathrm{q}_{\mathrm{U}}$ for all composites-excluding composite "ak" with A300/mod. A174.

The obvious increasing of chemical durability in c. $\mathrm{HNO}_{3}$ takes place in case of filling by A300/mod.A174 (Figure 1). Modification of A300 with an acrylsilane A174 can prolong a life time of EP in 1.5 time (15 days for unfilled EP, 25 days for "ak", Figure 1), and at the same time a swelling obviously decreases $\left(\mathrm{q}_{\mathrm{ak}}<\mathrm{q}_{\mathrm{U}}\right)$. It can reflect the formation of more stable and less-penetrating polymeric chain compared with unfilled or unmod.A-300 filled EP-composite.

Increasing of $q$ after filling as a rule can be evaluated as a negative factor (that is obvious for A-300, Figure 1), but in some cases it is a positive factor. For A300/mod. Bis-GMA, increasing of q due to maximal elasticity, that let prolong life-time of EP-composite. At last stages (20 25 days), composite swell at $q \geq 100 \%$. As a result, the template transforms from lens- to ball-form (Figure 6), but does not decompose during 25 days, whereas unfilled EP (or EP filled by pure A300) decomposes after 15 days (Figure 1).

Thus, the introduction of nanosilica in the epoxy composite is capable to reduce at $10 \%-30 \%$ the degree of swelling in concentrated nitric acid, depending on exposure time and specific surface area of NS. At some conditions $\left(10^{\circ} \mathrm{C}\right)$ the correlation $\mathrm{q} \sim 1 / \mathrm{S}(\mathrm{S}$-surface area of NS) takes place. Modification of NS by silanes and acrylates can increase the chemical resistance of composites at optimal concentrations and modificators of NS. For example, $\mathrm{q}<\mathrm{q}_{\mathrm{U}}$ and $\mathrm{L} \square \quad \mathrm{L}_{\mathrm{U}}\left(\mathrm{q}_{\mathrm{U}}\right.$ and $\mathrm{L}_{\mathrm{U}}$-for Unfilled EP-composite) for $5 \mathrm{wt} \%$ unmod.A-100 and A-300 modified by propylmethacrylate-trimethoxysylane A174, or A-300, modif.by Bis-GMA.

Change of the chemical resistance of composites under the influence of small additions of nanosilica is primarily due to its influence on the structure of the composites. This is illustrated by TEM-micrographs and X-rays of composites are shown in Figure 7. As can be seen from the figure, the structure of unfilled epoxy composite (A) is almost homogeneous, and filled $(2-5 \mathrm{wt} \%)$ by silica A-100/mod. A-174 (B) and A-100/mod.MTES + ED-5 (B) - nanoheterogenous structure (two-phase). The size and shape of aggregates of the dispersed phase of silica in polyepoxide matrix depend on the type of modified silica. 


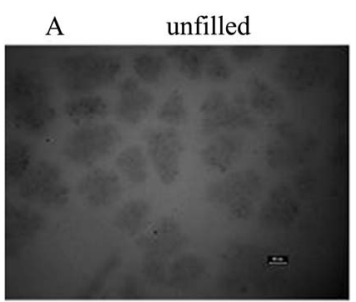

B A-100/MTES+Epox

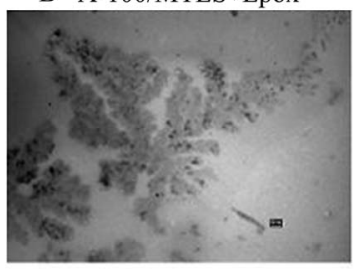

C A-100/acrylsilane

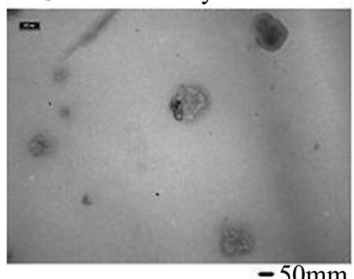

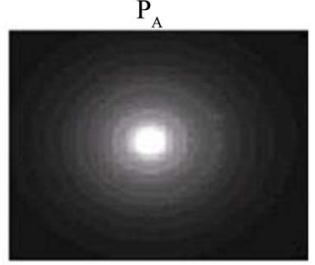

$\mathrm{P}_{\mathrm{B}}$

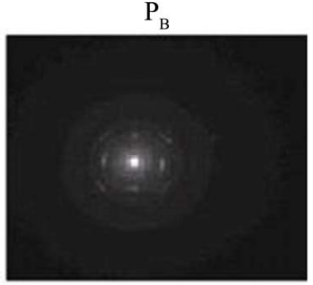

$P_{C}$

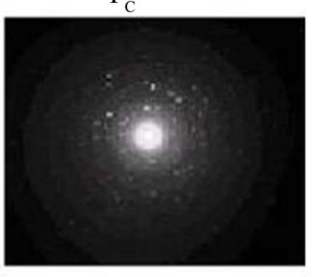

Figure 7. Photomicrographs and X-ray of unfilled sample polyepoxides (A) filled with $2 \%$ aerosil A-100, modified MTES and ED-5 (B) and modified by acrylate silane A-174 (C).

It can be seen in roentgenograms of the composites that the introduction of modified silica leads to a change in the structure of the composite, for example, in the form of ordered zones. So, after filling, on X-ray images are visible white blotches. Such inclusions, according to [20,21], are characteristics of the crystallization zone or structure in the polymer matrix. This means that the introduction of modified aerosil may create a zone in the polymer with a more ordered structure, like a crystal. The number of these zones depends on the method of modification. They are visible on a roentgenograms of a composite with $\mathrm{SiO}_{2}$ /modif.by silane MTES (Figure 7, sample B). Even greater extent, such changes can be seen in the sample B (Figure 7) - with silica modified by A174 (sample "AK5"), and this could explain the increased chemical resistance in conc. $\mathrm{HNO}_{3}$ after filling this polymer with silica.

\section{Conclusions}

1) Introduction of nanosilica leads to increased chemical resistance of polyepoxides in aggressive environments, which is illustrated by the example of swelling of the composites in concentrated nitric acid.

2) Swelling of the filled polyepoxides in concentrated $\mathrm{HNO}_{3}$ depends on the specific surface of silica. Under certain conditions $\left(10^{\circ} \mathrm{C}\right)$ decreasing of swelling rate correlates with increasing of specific surface area.
3) The surface modification of silica is an effective way for increasing of a swelling resistance of the composite polyepoxides.

4) TEM and X-ray analysis of polyepoxide samples showed that modification of silica surface leads to a noticeable change in the structure of the composite. In particular, that is possible due to formation of $\mathrm{SiO}_{2}$-nanoinclusions in the polymer and ordered zones in the structure of the polymer.

\section{REFERENCES}

[1] X. D. Shi and S. G. Croll, "Recovery of Surface Defects on Epoxy Coatings and Implications for the Use of Accelerated Weathering," Progress in Organic Coatings, Vol. 67, No. 2, 2010, pp. 120-128. doi:10.1016/i.porgcoat.2009.10.012

[2] A. D. Eselev, O. N. Garicheva, I. A. Chmutin and V. Serbin, "Using of Nanoadditives in Obtaining of Epoxy Flooring Composites," Coating Industry (Russian), No. 1, 2009, pp. 18-24.

[3] G. P. Tishchenko, A. A. Radula, A. V. Onishchenko and A. K. Zhugaylo, "Investigation of the Effect of Different Methods of Modification on the Stability of Epoxy-Basalt Coatings in Food Environments," Problems of Chemistry and Chemical Technology (Russian), No. 1, 2009, pp. 140-145.

[4] M.-Y. Chen, C.-R. Chen, S.-H. Hsu, S.-P. Sun and W.-F. $\mathrm{Su}$, "Low Shrinkage Light Curable Nanocomposite for Dental Restorative Material," Dental Materials, Vol. 22, No. 2, 2006, pp. 138-145. doi:10.1016/j.dental.2005.02.012

[5] J. Batler, N. Becker, M. Ziehmer, M. Thomassey, B. Zielinski, U. Müller and R. Sanctuary, "Interactions between Silica Nanoparticles and an Epoxy Resin before and during Network Formation," Polymer, Vol. 50, No. 14, 2009, pp. 3211-3219. doi:10.1016/j.polymer.2009.05.020

[6] Y. P. Zheng, Y. Zheng and R. C. Ning, "Effects of Nanoparticles $\mathrm{SiO}_{2}$ on the Performance of Nanocomposites," Materials Letters, Vol. 57, No. 19, 2003, pp. 2940-2944. doi:10.1016/S0167-577X(02)01401-5

[7] G. M. Magomedov, S. A. Abakarov, M. R. Magomedov, A. A. Seagull, O. A. Serenko and S. L. Bazhenov, "Effect of $\mathrm{SiO}_{2}$ Nanoparticles on the Electrical and Viscoelastic Properties of Epoxy Composites," Proceedings of the 10th International Conference "Oligomers-2009", Volgograd, 2009, p. 241.

[8] D. L. Starokadomsky, "The Influence of Dispersion and Concentration of Aerosil in Polyepoxydes Composites on Their Swelling in Acidic Media," Ukrainian Chemical Journal, Vol. 76, No. 7-8, 2010, pp. 89-96.

[9] V. A. Kochetkov and R. D. Maksimov, "Water Absorption and Swelling of Glass/Epoxy Syntactic Foams," Mechanics of Composite Materials, Vol. 32, No. 1, 1996, pp. 61-70. doi:10.1007/BF02254649

[10] D. Starokadomsky and I. Telegeyeff, "Influence of Nature and Concentration of Silica on Swelling (in Water/Acid Environments) and Structure of Polyepoxy Composites," 
Research \& Reviews in Polymer, Vol. 1, No. 1, 2010.

[11] D. L. Starokadomsky, "Influence of Heat Treatment on Swelling of Polyepoxide Composition," Proceedings of the 16th International Conference on "Mechanics of Composite Materials", Riga, 24-28 May 2010, pp. 2-10.

[12] I. Krakovský, J. Pleštil and L. Almásy, "Structure and Swelling Behavior of Hydrophilic Epoxy Networks Investigated by SANS," Polymer, Vol. 47, No. 1, 2006, pp. 218-226. doi:10.1016/i.polymer.2005.11.021

[13] N. N. Trofimov, V. P. Pathrusim, K. A. Shatskaya, et al., "The Influence of Processing Glass Fiber Reinforcement Materials in a Plasma on the Strength and Water Resistance of Glass-Reinforced Plastics Based on Them," Plastics, No. 5, 2005, pp. 13-16.

[14] Y.-L. Liu, C.-Y. Hsua, W.-L. Weia and R.-J. Jeng, "Preparation and Thermal Properties of Epoxy-Silica Nanocomposites from Nanoscale Colloidal Silica," Polymer, Vol. 44, No. 18, 2003, pp. 5159-5167. doi:10.1016/S0032-3861(03)00519-6

[15] D. L. Starokadomsky, "The Content of the Unmodified Silica with Different Specific Surface Effect on the Mechanical Properties of Polyepoxy Composites," Russian Journal of Applied Chemistry, Vol. 81, No. 12, 2008, pp. 2045-2051.

[16] E. L. McKague Jr., J. D. Reynolds and J. E. Halkias, "Swelling and Glass Transition Relations for Epoxy Ma- trix Material in Humid Environments," Journal of Applied Polymer Science, Vol. 22, No. 6, 1978, pp. 16431654.

[17] H. Yim, M. Kent and W. F. McNamara, "Structure within Thin Epoxy Films Revealed by Solvent Swelling: A Neutron Reflectivity Study," Macromolecules, Vol. 32, No. 23, 1999, pp. 7932-7938. doi:10.1021/ma990990c

[18] N. Yoshizawa, K. Maruyama, T. Yamashita and A. Akimoto, "Dependence of Microscopic Structure and Swelling Property of DTF Chars upon Heat-Treatment Temperature," Fuel, Vol. 85, No. 14-15, 2006, pp. 2064-2070. doi:10.1016/j.fuel.2006.04.005

[19] Y. Y. Choi, S. H. Lee and S. H. Ryu. "Effect of Silane Functionalization of Montmorillonite on Epoxy/Montmorillonite Nanocomposite," Polymer Bulletin, Vol. 63, No. 1, 2009, pp. 47-55.

[20] S. N. Danilchenko, "The Morphology and Crystal Structure of Biogenic Apatite According to Transmission Electron Microscopy and Electron Diffraction," Bulletin of Sumy State University (Series of Physics, Mechanics), No. 2, 2007, pp. 94-100.

[21] A. I. Buvaylo, L. P. Oleksenko, N. P. Maksimovich, I. P. Mother, I. Kotenko, E. V. Juice and G. I. Skolyar, "Electron-Semiconductor Gas Sensor Based on $\mathrm{H}_{2}$-Oxide $\mathrm{Na}$ nomaterials," Problems of Chemistry and Chemical Technology," No. 6, 2009, pp. 151-154. 